\title{
EPIDEMIOLOGICAL, CLINICALE THERAPEUTIC PROFILE OF PATIENTS WITH PRIMARY SJÖGREN SYNDROME IN A TERTIARY HOSPITAL OF SÃO PAULO/SP
}

Gabriele Souza Moulin Vago ${ }^{1, \star}$, Juliana D Agostino Gennari ${ }^{1}$, Dawton Yukito Torigoe ${ }^{1}$, Renata Sanzovo Pires de Campos Bellan ${ }^{1}$, Andrea Alonso Negrini ${ }^{1}$, Rachel Ribeiro Fernandes ${ }^{1}$, Rene Lima Porto ${ }^{1}$

1. Hospital Santa Casa de São Paulo, São Pulo (SP), Brazil.

*Corresponding author: gabrielemoulin.reumato@gmail.com

\section{BACKGROUND}

Primary Sjögren's syndrome (Ssp) is a chronic, slow and progressive disease which is characterized by lymphocyte infiltrate that affects the epithelium of the exocrine glands, mainly salivary and lacrimal. It is a systemic disease with high risk of transformation to lymphoma, which can affect the joints, lungs, kidneys, central and peripheral nervous systems. Given the difficulties in the diagnosis of these patients and the scarcity of epidemiological studies of patients with Ssp in Brazil, this study sought to trace the profile of these patients through the experience of the rheumatology department of a Brazilian school hospital.

\section{MATERIALS AND METHODS}

An observational, longitudinal, retrospective and descriptive study was carried out by means of electronic medical record data collection from October 2018 to October 2019. Data from 26 patients were analyzed, after the inclusion criteria was met: age older than 18 years old; diagnosis of Ssp according to the ACR/EULAR 2016 criteria; secondary Sjögren's syndrome; sicca secondary symptoms due to the use of medicines; previous head and neck radiotherapy; hepatitis $C$ carriers and acquired immunodeficiency syndrome (AIDS); pre-existing lymphoma was excluded; sarcoidosis; graft versus host disease; or using anticholinergic drugs. The collected information was tabulated according to: age, sex, presence or absence of antinuclear factor, anti-Ro/SS-A, anti-La/SS-B, rheumatoid factor (FR), disease-related characteristics (glandular and extra glandular manifestations), comorbidities, medications being used for the treatment of Ssp, salivary gland biopsy results.

\section{RESULTS}

Regarding to the general characteristics of the casuistry, we verified that $96.15 \%$ of the evaluated patients are female and $3.84 \%$ male; mostly above 41 years old ( $84.6 \%$ ). Around $88.46 \%$ present positive anti-Ro/SS-A; $46.15 \%$ anti-La/SS-B and FR. Almost all of the patients (25) were using disease-modifying drugs, among them seven with association to some immunosuppressant (azathioprine, mycophenolate mofetyl). Minor salivary gland biopsy performed in 12 patients was compatible with the diagnosis of Ssp in 10 of them (83\%). Among the complaints, about $88.46 \%$ of the patients presented xerostomia or xerophthalmia. The most associated comorbidities were: systemic arterial hypertension (66.6\%), hypothyroidism (50\%), fibromyalgia (38.8\%) and diabetes mellitus (16.6\%).

\section{CONCLUSION}

This study has found results in agreement with other epidemiological studies, highlighting an important role in being one of the first to trace the clinical and epidemiological profile of patients with defined diagnosis of Ssp in a tertiary health service. 